\title{
Association of Tourette Syndrome and Chronic Tic Disorder With Subsequent Risk of Alcohol- or Drug-Related Disorders, Criminal Convictions, and Death : A Population-Based Family Study
}

\section{Virtanen, Suvi}

2021-02-15

Virtanen , S , Sidorchuck, A, Fernández de la Cruz , L, Brander , G, Lichtenstein , P , Latvala , A \& Mataix-Cols , D 2021 , ' Association of Tourette Syndrome and Chronic Tic Disorder With Subsequent Risk of Alcohol- or Drug-Related Disorders, Criminal Convictions, and Death : A Population-Based Family Study ' , Biological Psychiatry, vol. 89 , no. 4 , pp. 407-414 . https://doi.org/10.1016/j.biopsych.2020.09.014

http://hdl.handle.net/10138/334520

https://doi.org/10.1016/j.biopsych.2020.09.014

cc_by_nc_nd

acceptedVersion

Downloaded from Helda, University of Helsinki institutional repository.

This is an electronic reprint of the original article.

This reprint may differ from the original in pagination and typographic detail.

Please cite the original version. 


\section{Association of Tourette syndrome and chronic tic disorder with subsequent risk of alcohol- or drug-related disorders, criminal convictions, and death: a population-based family study}

Suvi Virtanen ${ }^{1,2}$, Anna Sidorchuk ${ }^{3,4}$, Lorena Fernández de la Cruz $^{3,4}$, Gustaf Brander ${ }^{3,4,5}$, Paul Lichtenstein ${ }^{2}$, Antti Latvala ${ }^{1,2}$, David Mataix-Cols ${ }^{3,4}$

\footnotetext{
${ }^{1}$ Institute of Criminology and Legal Policy, University of Helsinki, Helsinki, Finland

${ }^{2}$ Department of Medical Epidemiology and Biostatistics, Karolinska Institutet, Stockholm, Sweden

${ }^{3}$ Centre for Psychiatry Research, Department of Clinical Neuroscience, Karolinska Institutet, Stockholm, Sweden

${ }^{4}$ Stockholm Health Care Services, Region Stockholm, Stockholm, Sweden

5 Department of Medical Biochemistry and Microbiology, Uppsala University, Uppsala, Sweden
}

Corresponding author: Suvi Virtanen, Institute of Criminology and Legal Policy, University of Helsinki, P.O. Box 24 (Unioninkatu 40), FI-00014, University of Helsinki, Finland, (suvi.virtanen@helsinki.fi).

Running title: The association of tic disorders with substance misuse

Keywords: Alcohol, drugs, tic disorders, Tourette Syndrome, longitudinal, family study 


\section{Abstract}

Background: It remains unclear if individuals with Tourette syndrome (TS) or chronic tic disorder (CTD) have an elevated risk of subsequent substance misuse.

Methods: In this population-based cohort study, we investigated the association between International Classification of Diseases (ICD) diagnoses of TS/CTD and substance misuse outcomes accounting for psychiatric comorbidity and familial factors. The cohort included all individuals living in Sweden at any time between January 1, 1973 and December 31, 2013. Substance misuse outcomes were defined as an ICD-code of substance use-related disorder or cause of death, or as a substance use-related criminal conviction in the nationwide registers.

Results: The cohort included 14,277,199 individuals, of which 7,832 had a TS/CTD diagnosis (76.3\% men). TS/CTD was associated with an increased risk of any subsequent substance misuse outcome (adjusted hazard ratio [aHR]=3.11, [95\% Cl: 2.94-3.29]), including alcohol-related disorder (aHR=3.45, [3.19-3.72]), drug-related disorder (aHR=6.84, [6.32-7.40]), substance-related criminal convictions (aHR=2.56, [2.36-2.77]), and substancerelated death (aHR=2.54, [1.83-3.52]). Excluding psychiatric comorbidities had little effect on the magnitude of the associations, with the exception of attention-deficit/hyperactivity disorder, which attenuated the risk of any substance misuse outcomes (aHR=2.00, [1.822.19]). The risk of any substance misuse outcomes in individuals with TS/CTD was substantially attenuated but remained significant when compared to their unaffected siblings (aHR=1.74, [1.53-1.97]).

Conclusions: TS/CTD were associated with various types of subsequent substance misuse outcomes, independently of psychiatric comorbidity and familial factors shared between siblings. Screening for drug and alcohol use should become part of the standard clinical routines, particularly in patients with comorbid attention-deficit/hyperactivity disorder. 


\section{Introduction}

Tourette syndrome (TS) and chronic tic disorder (CTD) are childhood-onset neurodevelopmental movement disorders characterized by multiple motor and/or at least one vocal tic persisting for more than one year (1). TS/CTD affect approximately $0.5-1 \%$ of the population (2). A majority of patients (70-90\%) have comorbid psychiatric conditions, including attention-deficit/hyperactivity disorder (ADHD), obsessive-compulsive disorder (OCD), autism spectrum disorders, mood disorders, and anxiety disorders (3-5).

Despite the great personal and societal relevance, substance misuse has rarely been studied in the field of tic disorders, with many large cohort studies not even evaluating it (46). One possible reason is that most patients with TS/CTD are seen in pediatric settings and not followed-up into adulthood, the period of highest risk for substance misuse (7-9). In a rare cross-sectional study of psychiatric comorbidity in TS (3), approximately $6 \%$ of a clinically ascertained sample of 948 individuals with TS had a recorded lifetime substance use disorder, with no differences between men and women. The prevalence of substance use disorder was $2.6 \%$ in TS-affected adolescents and $18.5 \%$ in adults. Therefore, a nonnegligible proportion of adults with TS may develop substance use-related problems over time, but large epidemiological studies with prospectively collected data and long-term follow-ups are needed to fully capture the risk of substance misuse in this patient group.

Given that psychiatric comorbidity is the norm rather than the exception in TS/CTD (3-6) and the known association between psychiatric disorders and substance misuse, $(10,11)$ the relationship between TS/CTD, psychiatric comorbidities, and substance misuse outcomes is likely to be complex. A plausible hypothesis is that individuals with TS/CTD have an elevated risk of substance misuse at least partially attributable to the psychiatric comorbidities. However, this needs to be confirmed in much larger patient cohorts with sufficient statistical power. Even if the associations were explained by comorbid conditions, it would not make the findings less important, as substance use disorders are still likely to require specific clinical attention in individuals with TS/CTD. 
If TS/CTD were associated with increased risk of substance misuse, the next logical step would be to attempt to understand the underlying mechanisms. The potential associations could be due to etiological factors shared between the two conditions, such as genetic liability or shared environmental risk factors $(12,13)$. Alternatively, the association could reflect causal mechanisms, meaning that TS/CTD would causally increase the risk of substance misuse, over and above shared genetic and environmental influences between the two disorders. For example, individuals with TS/CTD may use alcohol or drugs to cope with their tics and associated comorbidities (self-medication hypothesis) $(14,15)$. Genetically informative designs, such as comparing discordant twins or siblings from the same biological parents, are ideally suited to evaluate these alternative hypotheses.

In this study, we leveraged the unique Swedish population-based registers and identified one of the world's largest cohorts of prospectively followed patients with TS/CTD to: 1) estimate the risk of alcohol- or drug-related disorders, criminal convictions, and death in individuals with TS/CTD at the population level, 2) establish the extent to which the association between TS/CTD and various types of substance misuse outcomes is explained by psychiatric comorbidity, and 3) investigate whether the association is influenced by familial factors shared by siblings. 


\section{Methods and Materials}

\section{Study cohort}

The study cohort included all individuals living in Sweden at any time between January 1 , 1973 and December 31, 2013 identified through the Swedish Total Population Register. A personal identity number is assigned to each individual in Sweden at birth or immigration, allowing linkage between different registers (16). We linked the cohort to the National Patient Register (NPR), the Crime Register, the Cause of Death Register, the Migration Register, and the Multi-Generation Register, which can be used to link individuals with their parents, and thus to identify siblings (17-20). The cohort was followed up through the registers from 1973 or the $10^{\text {th }}$ birthday, whichever came last, until the end of 2013 . The study was approved by the Regional Ethical Review Board in Stockholm.

\section{Tourette syndrome and chronic tic disorder}

We identified individuals with a lifetime diagnosis of TS or CTD registered between 1973 and 2013 from the NPR, which covers inpatient (1973-) and outpatient (2001-) International Classification of Diseases (ICD) diagnoses nationwide. Diagnoses of TS/CTD were ascertained using the Swedish versions of the ICD-8 (306.2), ICD-9 (307C), and ICD-10 (transient tic disorder: F95.0, chronic motor or vocal tic disorder: F95.1, Tourette syndrome: F95.2, other tic disorders: F95.8, or unspecified tic disorder: F95.9). We used an algorithm to minimize the inclusion of individuals with only transient tics and excluded diagnoses registered before the age of three to further minimize the risk of misdiagnosis $(21-23)$. The validity and reliability of the ICD codes for TS/CTD in the NPR are excellent but clinicians tend to use the TS and CTD codes interchangeably, precluding separate analyses for these tic disorder subtypes (24). 
We defined substance misuse outcomes as any ICD-8, ICD-9, or ICD-10 codes for the diagnoses of mental and behavioral disorders due to psychoactive substance use, alcohol/drug-related somatic conditions, or poisoning by alcohol or drugs, registered between 1973 and 2013 in the NPR (diagnostic codes in Table S1). We also included alcohol/drug-related deaths and criminal convictions from the registers. Causes of death consisted of ICD codes for acute intoxication and poisoning due to alcohol or drugs, and alcohol- or drug-related somatic conditions (Table S2). To ensure the validity of the outcomes, we excluded registrations before age 10. Alcohol/drug-related criminal convictions were retrieved from the Crime Register, including driving under the influence of alcohol/drugs and violations of the Narcotic Drugs Act such as possession, manufacturing, trafficking, or sales of narcotics. The minimum age for criminal responsibility in Sweden is 15.

\section{Psychiatric comorbidities}

To investigate whether psychiatric comorbidities contributed to the risk of substance misuse outcomes, we included lifetime diagnoses of the following psychiatric disorders or groups of disorders from the NPR: 1) ADHD, 2) conduct disorders, 3) pervasive developmental disorders, 4) OCD, 5) anxiety disorders, 6) depressive disorders, and 7) psychotic and bipolar disorders (Table S3).

\section{Statistical analyses}

For aim 1, we used Cox proportional hazards regression, with age in years as the underlying time-scale, to estimate the association between lifetime TS/CTD and different substance misuse outcomes. The risk of alcohol/drug-related disorders (any disorder and specific alcohol/drug-use disorders), alcohol/drug-related criminal convictions, and alcohol/drugrelated deaths in individuals with TS/CTD was compared to that of unaffected individuals in 
the general population. Participants were followed up from 1973 or their $10^{\text {th }}$ birthday, whichever occurred last, until the date of first substance misuse outcome, emigration, death, or December 31, 2013, whichever occurred first. All models were adjusted for sex and birth year. We present estimates both for the full sample and separately for men and women.

In order to ensure that the observed associations were not biased due to lack of data coverage (e.g., exposure/outcome occurring before the start of the follow-up), we repeated the main analyses in a sub-cohort of individuals born after 1972 with follow-up from birth. Using this cohort, we also estimated the cumulative incidence of the different types of substance misuse outcomes for individuals with and without TS/CTD using Kaplan-Meier survival estimates under the assumption of no competing risks (estimated as 1 minus the Kaplan-Meier estimate of survival function).

For aim 2, we repeated the main analyses excluding different groups of comorbid psychiatric disorders, one at a time, to establish the extent to which the association between TS/CTD and different types of substance misuse outcomes was explained by psychiatric comorbidity.

For aim 3, we investigated the associations between TS/CTD and substance misuse in a subsample of full siblings within the cohort, identified as individuals who share both biological parents. We used Cox proportional hazard regression models stratified by sibling clusters, which rule out all factors constant within full siblings (i.e., on average $50 \%$ of genetic factors and shared environmental influences as, for example, parental socioeconomic status) $(25,26)$. Such within-family fixed effects models (27) use information from clusters with discordance in the exposure by comparing the individual with TS/CTD with their unaffected siblings. We excluded monozygotic twins from the analyses.

Due to the small number of cases, alcohol/drug-related deaths were not separately addressed in the analyses for aims 2 and 3. Statistical analyses were conducted between 
October 10, and December 20, 2019 with Stata version 14 (StataCorp LP). SAS, version 9 (SAS Institute Inc.), was used for data management.

\section{Results}

\section{Descriptive statistics}

The study cohort included $14,277,199$ individuals with a median length of follow-up of 25.6 years (interquartile range: 12.7-40.7). Altogether, 7,832 individuals were diagnosed with TS/CTD between 1973 and 2013, of which 5,977 were men (76.3\%) and 1,855 were women (23.7\%). The median age at first TS/CTD diagnosis registration was 13.4 years (interquartile range: $10.0-21.8$ ) in the total cohort, and 12.3 years (interquartile range: $9.5-16.9$ ) in those with follow-up from birth.

Risk of alcohol- or drug-related disorders, criminal convictions, and deaths

Individuals with TS/CTD had 3.11 (adjusted for sex and birth year, 95\% Cl: 2.94-3.29) times greater risk of any subsequent substance misuse outcome, compared to the unaffected general population (Table 1). Specifically, TS/CTD were associated with an increased risk of alcohol-related disorder (adjusted hazard ratio [aHR]=3.45, Cl: 3.19-3.72), any drug-related disorders (aHR=6.84, Cl: 6.32-7.40), substance-related criminal convictions (aHR=2.56, $\mathrm{Cl}$ : 2.36-2.77), and substance-related death $(\mathrm{aHR}=2.54, \mathrm{Cl}: 1.83-3.52)$. The highest relative risk estimates were for the disorders due to stimulants (aHR=9.60,95\% Cl: 8.28-11.14) and sedatives (aHR=9.04, 95\% Cl: 8.03-11.17).

Analyses stratified by sex indicated that men with TS/CTD had a higher relative risk of alcohol-related disorder than the corresponding risk estimated for women with TS/CTD, whereas women had a higher relative risk of drug-related disorders (Table 1). When looking at specific drug-related disorders, estimates for all types of drugs (except for sedatives) were 
higher in women, but confidence intervals were non-overlapping only for disorders due to cannabis. The relative risk of criminal convictions in individuals with TS/CTD was also higher in women than men with TS/CTD, as suggested by the non-overlapping Cls.

In analyses limited to those with follow-up from birth, the risks for different alcoholand drug-related outcomes attenuated slightly, but were overall very similar to the main analyses (Table S4). We estimated the cumulative incidence of different substance misuse outcomes in the same subsample (Figure 1). The cumulative incidence of alcohol-related disorders in individuals diagnosed with TS/CTD exceeded $20 \%$ by age 41 ( $9 \%$ in the general population) and was $26 \%$ for drug-related disorders ( $4 \%$ in the general population). The cumulative incidence of substance-related convictions was $20 \%$ in TS/CTD individuals (6\% in the general population). For substance-related deaths, the cumulative incidence reached slightly over $1 \%$ by age 41 in those with TS/CTD (less than $0.5 \%$ in the general population). Differences between individuals with TS/CTD and unaffected individuals in the incidence of alcohol-related disorders, drug-related disorders, and substance-related criminal convictions were evident by age 16, and for substance-related deaths by age 33 (non-overlapping 95\% Cls).

\section{Role of psychiatric comorbidities}

As expected, there was extensive psychiatric comorbidity in the TS/CTD cohort with $71.6 \%$ of individuals with a record of at least one psychiatric disorder (Table S5). ADHD was the

most common comorbidity ( $46 \%$ of the cohort), followed by pervasive developmental disorders (25.7\%) and anxiety disorders (25.4\%). Exclusion of different groups of psychiatric comorbidities, one at the time, resulted in negligible attenuation in the estimates, with the exception of anxiety disorders, and particularly ADHD (Table 2). Based on non-overlapping Cls in the estimates, excluding individuals with ADHD and anxiety disorders significantly decreased, but did not eliminate, the risk of different substance misuse outcomes in individuals with TS/CTD. The elevated risk of substance misuse outcomes persisted even 
when all psychiatric comorbidities were excluded at the same time (rightmost column, Table 2)

Within-family analyses

The cohort included 2,789,875 families with at least two full siblings, of which 5,310 were discordant for TS/CTD. We observed a marked attenuation in the magnitude of the associations between TS/CTD and substance misuse outcomes, compared to the estimates from the main analyses (Table 3), but the risks for any substance misuse outcome, alcoholrelated disorder, any drug-related disorder, and substance-related criminal convictions were still significantly higher in individuals with TS/CTD, compared to their unaffected siblings. 


\section{Discussion}

To our knowledge, this is the first study to prospectively investigate the association between TS/CTD and subsequent substance misuse outcomes. The main findings were that individuals with TS/CTD were at increased risk of subsequent alcohol-related disorders, drug-related disorders, substance-related criminal convictions, and substance-related deaths, even after controlling for unmeasured familial confounders and accounting for psychiatric comorbidities. In particular, compared to the unaffected general population, individuals with TS/CTD had nearly a 7-fold increased risk of any drug-related disorder (including cannabis, opioids, sedatives, and stimulants), over a 3-fold increased risk of alcohol-related disorder, and a 2.5-fold increased risk of both substance-related criminal convictions and substance-related deaths.

For the sub-cohort followed from birth, the expected cumulative incidence of alcoholrelated disorders in individuals with TS/CTD exceeded 20\% by age 41 (end of the follow-up period), reached $26 \%$ for drug-related disorders, and $20 \%$ for substance-related convictions. The corresponding figures in the general population were $9 \%, 4 \%$, and $6 \%$, respectively, in line with recent Danish studies, $(28,29)$. While substance-related deaths were rare in the TS/CTD cohort (about 1\%), they were still significantly more common than in the general population (less than $0.5 \%$ during the same follow-up period). Higher incidence of alcohol- or drug-related disorders and criminal convictions in individuals with TS/CTD was already evident by age 16 . These results strongly suggest that regular screening for substance use should be an important aspect of the routine clinical management of these patients, even in pediatric and child psychiatry settings.

While the risk of substance misuse was elevated both in men and in women with TS/CTD, we also observed some noteworthy sex differences. In particular, men with TS/CTD had a higher relative risk of alcohol-related disorders compared to women with TS/CTD, whereas women had a higher relative risk of drug-related disorders, particularly cannabis use disorders, and criminal convictions. However, these findings do not reflect 
absolute differences between men and women, but rather the lower baseline risk of substance misuse outcomes among women in the general population. In terms of absolute risks, men and women with TS/CTD had largely similar prevalences of substance-related outcomes.

A second aim of the study was to explore whether the risk of substance misuse in individuals with TS/CTD could be explained by psychiatric comorbidities. This is important because many psychiatric disorders are associated with alcohol/drug-related outcomes $(10,11,30)$. In general, the exclusion of different groups of psychiatric comorbidities, one at the time, did not significantly alter the magnitude of the estimates, although this risk was attenuated when ADHD and anxiety disorders were excluded. Specifically, individuals without comorbid ADHD still had a 4 times higher risk of drug-related disorders, over 2 times higher risk of alcohol-related disorders, and 1.6 times higher risk of substance-related criminal convictions. Therefore, TS/CTD are associated with increased risk of substance misuse outcomes in their own right, but individuals with comorbid ADHD seem to be at particularly high risk. This is unsurprising given the known association between ADHD and harms caused by alcohol and drugs (31-33).

A third aim of the study was to shed some light on the potential mechanisms behind the observed associations. In the sibling comparison analyses, the magnitude of the risk estimates approximately halved. This degree of attenuation is compatible with a shared familial liability between TS/CTD and substance misuse outcomes. Indeed, there may be pleiotropic genetic effects $(12,13)$ and/or shared environmental risk factors (e.g., socioeconomic status) that may partially influence both the TD/CTD and alcohol- or drugrelated disorders. Future family co-aggregation or twin studies are needed to quantify the extent to which genetic and environmental risk factors are shared across these disorders. Nevertheless, the risk of alcohol- or drug-related disorders and criminal convictions remained statistically significant in the sibling comparisons. That is, siblings affected by TS/CTD still had significantly elevated risk of substance misuse outcomes, compared with 
their unaffected siblings. Because sibling comparisons account for only $50 \%$ of genetic influences, most of the observed associations between TS/CTD and substance misuse may still be genetically driven, but other potential causal mechanisms may be at play, such as the possibility that patients with TS/CTD use alcohol or drugs to cope with their symptoms, in line with a self-medication hypothesis. The literature is sparse but some reports describe patients self-medicating with alcohol or marijuana and experiencing marked reductions of tics and associated symptoms (14), triggering promising new experimental research into the potential efficacy of cannabinoids in the treatment of tic disorders (34).

\section{Strengths and Limitations}

The main strengths of the current study are the large, population-based sample of individuals with TS/CTD, the long follow-up spanning up to 41 years, the high validity of the diagnostic codes, (24) the use of nationwide registers with prospective and uniformed data collection which minimizes the risk of selection, recall, and report biases, and the use of a sibling design which takes into account unobserved familial confounding potentially contributing to the observed associations.

Some important limitations are worth discussing. First, due to the help-seeking nature of the TS/CTD cohort, the results may not generalize to milder or transient forms of tic disorders that may not require or seek contact with the health services. Nevertheless, the individuals with TS/CTD included in our cohort are very similar to those described in the international literature, and thus our results are likely to generalize to patients seen in specialist clinics around the world (4). Similarly, the coverage of the alcohol- and drugrelated disorders cases is incomplete because the patient register only captures individuals with a severe enough clinical presentation to require treatment in specialist inpatient and outpatient services. In Sweden, less severe cases are often treated at the primary care level (35) which is not covered by the NPR, and treatment underutilization for substance use problems is common. 
Second, although the diagnoses of TS/CTD and substance misuse outcomes were recorded independently several years apart, we cannot rule out a degree of surveillance bias, whereby various outcomes due to alcohol or drugs may be more likely to be detected in individuals who are already in the health system due to TS/CTD. This limitation was somewhat mitigated by the inclusion of information from the Crime Register and the Cause of Death Register, which are independent from healthcare.

Third, while the validity and reliability of the ICD codes for TS/CTD are excellent, the validity of the SUD codes has not yet been formally examined. However, studies from other Nordic patient registers suggest adequate agreement between registered SUD diagnoses and diagnoses based on structured interviews by external examiners (36).

Fourth, we assumed that the majority of TS/CTD cases occur in early childhood, even if the diagnosis was only recorded later in life, and thus TS/CTD precedes substance misuse. In rare instances, substance misuse may have occurred before the onset of TS/CTD but, strictly speaking, TS/CTD should not be diagnosed if the tics are thought to be the direct result of a substance (e.g., cocaine).

\section{Conclusions and clinical implications}

TS/CTD are associated with subsequent alcohol and drug use disorders, and related outcomes, independently of psychiatric comorbidity and familial factors shared between siblings. The results have clear implications for the clinical management of these patients and strongly suggest that screening for drug and alcohol use should become part of the standard clinical routines, particularly in patients with comorbid ADHD. The results also highlight the importance of implementing preventive and early intervention strategies to preclude the onset and minimize the consequences of substance misuse in this patient group. However, it is important to note that the majority of individuals with TS/CTD do not have substance misuse problems, and that a TS/CTD diagnosis should not be automatically equated with problematic alcohol- or drug use. If the patient reports using substances, 
clinicians should carefully assess whether the diagnostic criteria for a substance use disorder are met to avoid misdiagnosis, as some patients may use substances, such as cannabis, to manage their symptoms (14) without necessarily developing harmful or hazardous use patterns. 


\section{Acknowledgements}

Funding/Support:

This study was supported by funding from the Academy of Finland grants 308698 and 314196, and the Swedish Research Council under the grant no. 2017-00641.

Role of the Funder/Sponsor:

The funding sources had no role in the design and conduct of the study; collection, management, analysis, and interpretation of the data; preparation, review, or approval of the manuscript; and decision to submit the manuscript for publication.

\section{Conflict of Interest Disclosures}

Prof. Mataix-Cols declares receiving personal fees from Elsevier and UpToDate, Inc, both outside the submitted work. Lorena Fernández de la Cruz receives royalties for contributing articles to UpToDate, Inc., outside the submitted work. Other authors report no conflicts of interest. 


\section{References}

1. American Psychiatric Association (2013): Diagnostic and Statistical Manual of Mental Disorders, 5th ed. Washington D.C.: American Psychiatric Publishing

2. Scharf JM, Miller LL, Gauvin CA, Alabiso J, Mathews CA, Ben-Shlomo Y (2015): Population prevalence of Tourette syndrome: A systematic review and metaanalysis. Mov Disord 30: 221-228.

3. Hirschtritt ME, Lee PC, Pauls DL, et al. (2015): Lifetime prevalence, age of risk, and genetic relationships of comorbid psychiatric disorders in Tourette syndrome. JAMA Psychiatry 72: 325-333.

4. Freeman RD, Fast DK, Burd L, et al. (2000): An international perspective on Tourette syndrome: selected findings from 3500 individuals in 22 countries. Dev Med Child Neurol 42: 436-447.

5. Robertson MM, Cavanna AE, Eapen V (2015): Gilles de la Tourette syndrome and disruptive behavior disorders: prevalence, associations, and explanation of the relationships. J Neuropsychiatry Clin Neurosci 27: 33-41.

6. Groth C, Debes NM, Rask CU, Lange T, Skov L (2017): Course of Tourette syndrome and comorbidities in a large prospective clinical study. J Am Acad Child Adolesc Psychiatry 56: 304-312.

7. Kraus L, Eriksson Tinghög M, et al. (2015): Age, Period and Cohort Effects on Time Trends in Alcohol Consumption in the Swedish Adult Population 1979-2011. Alcohol Alcoholism 50: 319-327.

8. Giordano GN, Ohlsson H, Kendler KS, et al. (2014): Age, period and cohort trends in drug abuse hospitalizations within the total Swedish population (1975-2010). Drug Alcohol Depend 134: 355-361. 
9. Kraus L, Østhus S, Amundsen EJ, et al. (2015): Changes in mortality due to major alcohol-related diseases in four Nordic countries, France and Germany between 1980 and 2009: a comparative age-period-cohort analysis. Addiction 110: 14431452.

10. Castillo-Carniglia A, Keyes KM, Hasin DS, Cerdá M (2019): Psychiatric comorbidities in alcohol use disorder. Lancet Psychiatry 6: 1068-1080.

11. Virtanen S, Kuja-Halkola R. Mataix-Cols D, Jayaram-Lindström N, D'Onofrio BM, Larsson H, Suvisaari J, Lichtenstein P, Latvala A (2020): Comorbidity of substance misuse with anxiety-related and depressive disorders: A genetically informative population study of 3 million individuals in Sweden. Psychol Med 50: 1706-1715.

12. Comings DE (1994): Genetic factors in substance abuse based on studies of Tourette syndrome and ADHD probands and relatives. I. Drug abuse. Drug Alcohol Depend 35: 1-16.

13. Comings DE (1994). Genetic factors in substance abuse based on studies of Tourette syndrome and ADHD probands and relatives. II. Alcohol abuse. Drug Alcohol Depend 35: 17-24.

14. Müller-Vahl KR, Kolbe H, Schneider U, Emrich HM (1998): Cannabinoids: possible role in patho-physiology and therapy of Gilles de la Tourette syndrome. Acta Psychiatr Scand 98: 502-506.

15. Müller-Vahl KR, Kolbe H, Dengler R (1997): Gilles de la Tourette-Syndrom: einfluss von nikotin, alkohol und marihuana auf die kliniche symptomatik. Nervenarzt 68: 985989.

16. Ludvigsson JF, Otterblad-Olausson P, Pettersson BU, Ekbom A (2009): The Swedish personal identity number: possibilities and pitfalls in healthcare and medical research. Eur J Epidemiol 24: 659-667. 
17. Ludvigsson JF, Andersson E, Ekbom A, et al. (2011): External review and validation of the Swedish National Inpatient Register. BMC Public Health 11: 450-466.

18. Ekbom A (2011): The Swedish Multi-generation Register. Methods Mol Biol 675: 215220.

19. Brooke HL, Talbäck M, Hörnbladet J, et al. (2017): The Swedish cause of death register. Eur J Epidemiol 32: 765-73.

20. Ludvigsson JF, Almqvist C, Bonamy AKE, et al. (2016): Registers of the Swedish total population and their use in medical research. Eur J Epidemiol 31: 125-36.

21. Brander G, Isomura K, Chang Z, Kuja-Halkola R, Almqvist C, Larsson H, Mataix-Cols D, de la Cruz LF (2019): Association of Tourette syndrome and chronic tic disorder with metabolic and cardiovascular disorders. JAMA Neurol 76: 454-461.

22. Isomura K, Brander G, Chang Z, et al. (2018): Metabolic and cardiovascular complications in obsessive-compulsive disorder: a total population, sibling comparison study with long-term follow-up. Biol Psychiatry 84: 324-331.

23. Perez-Vigil A, Fernandez de la Cruz L, Brander G, et al. (2018): Association of Tourette Syndrome and Chronic Tic Disorders With Objective Indicators of Educational Attainment: A Population-Based Sibling Comparison Study. JAMA Neurol 75: 1098-1105.

24. Rück C, Larsson KJ, Lind K, et al. (2015): Validity and reliability of chronic tic disorder and obsessive-compulsive disorder diagnoses in the Swedish National Patient Register. BMJ Open 5: e007520

25. Lahey BB, D'Onofrio BM (2010): All in the family: comparing siblings to test causal hypotheses regarding environmental influences on behavior. Curr Dir Psychol Sci 19: 319-323. 
26. D’Onofrio BM, Lahey BB, Turkheimer E, Lichtenstein P (2013): Critical need for family-based, quasi-experimental designs in integrating genetic and social science research. Am J Public Health 103: 46-55.

27. Gunasekara F, Richardson K, Carter K, Blakely T (2014): Fixed effects analysis of repeated measures data. Int J Epidemiol 43:264-269.

28. Pedersen CB, Mors O, Bertelsen A, Waltoft BL, Agerbo E, McGrath JJ, et al. (2014): A comprehensive nationwide study of the incidence rate and lifetime risk for treated mental disorders. JAMA Psychiatry 71: 573-81.

29. Mok PL, Antonsen S, Pedersen CB, Appleby L, Shaw J, Webb RT (2015): National cohort study of absolute risk and age-specific incidence of multiple adverse outcomes between adolescence and early middle age. BMC Public Health 15: 920930.

30. European Monitoring Centre for Drugs and Drug Addiction (2015): Comorbidity of substance use and mental disorders in Europe. In: EMCDDA Insights, 19. Luxembourg: Publications Office of the European Union.

31. Harstad E, Levy S (2014): Committee on Substance Abuse. AttentionDeficit/Hyperactivity Disorder and Substance Abuse. Pediatrics 134: e293

32. Capusan AJ, Bendtsen P, Marteinsdottir I, Kuja-Halkola R, Larsson H (2015): Genetic and environmental contributions to the association between attention deficit hyperactivity disorder and alcohol dependence in adulthood: a large populationbased twin study. Am J Med Genet B Neuropsychiatr Genet 168: 414-422.

33. Yule AM, Martleon M, Faraone S, Carrellas N, Wilens TE, Biederman J (2017): Examining the association between attention deficit hyperactivity disorder and substance use disorders: A familial risk analysis. J Psychiatr Res 85: 49-55. 
34. Artukoglu BB, Bloch MH (2019): The Potential of Cannabinoid-Based Treatments in Tourette Syndrome. CNS Drugs 33: 417-430.

35. Sundquist J, Ohlsson H, Sundquist K, Kendler KS (2017): Common adult psychiatric disorders in Swedish primary care where most mental health patients are treated. BMC Psychiatry 17: 234-244.

36. Øiesvold T, Nivison M, Hansen V, Skre I, Østensen L, Sørgaard KW (2013):

Diagnosing comorbidity in psychiatric hospital: challenging the validity of administrative registers. BMC Psychiatry 13: 13-20. 


\section{Tables}

Table 1. Prevalence and relative risk of substance misuse outcomes among individuals with Tourette syndrome or chronic tic disorder, compared with unaffected individuals from the general population and stratified by sex.

\begin{tabular}{|c|c|c|c|}
\hline \multirow[b]{2}{*}{ Substance misuse } & \multicolumn{3}{|l|}{ Individuals, no. (\%) } \\
\hline & $\begin{array}{l}\text { Tourette syndrome } \\
\text { or chronic tic } \\
\text { disorder cohort } \\
(n=7,832)\end{array}$ & $\begin{array}{l}\text { Unaffected } \\
\text { general } \\
\text { population } \\
(\mathrm{n}=14,269,367)\end{array}$ & $\begin{array}{l}\text { HR }(95 \% \mathrm{Cl}) \\
\text { adjusted for } \\
\text { sex and } \\
\text { birth year }\end{array}$ \\
\hline Any substance misuse outcomes ${ }^{\star}$, all & $1,241(15.9)$ & $972,349(6.8)$ & $3.11(2.94-3.29)$ \\
\hline Men & $966(16.2)$ & $667,439(9.3)$ & $3.30(3.09-3.51)$ \\
\hline Women & $275(14.8)$ & $304,910(4.3)$ & $3.73(3.31-4.20)$ \\
\hline Alcohol-related disorder", all & $658(8.4)$ & $545,903(3.8)$ & $3.45(3.19-3.72)$ \\
\hline Men & $494(8.3)$ & $331,072(4.6)$ & $4.53(4.14-4.95)$ \\
\hline Women & $164(8.8)$ & $214,831(3.0)$ & $2.94(2.52-3.43)$ \\
\hline Any drug-related disorder $\$$, all & $627(8.0)$ & $178,112(1.3)$ & $6.84(6.32-7.40)$ \\
\hline Men & $466(7.8)$ & $99,425(1.4)$ & $6.45(5.89-7.07)$ \\
\hline Women & $161(8.7)$ & $78,687(1.1)$ & $8.14(6.95-9.52)$ \\
\hline Disorders due to cannabis & $161(2.1)$ & $30,016(0.2)$ & $5.03(4.31-5.88)$ \\
\hline Men & $133(2.2)$ & $23,459(0.3)$ & $4.77(4.02-5.66)$ \\
\hline Women & $28(1.5)$ & $6,557(0.1)$ & $9.31(6.42-13.50)$ \\
\hline Disorders due to opioids & $142(1.8)$ & $39,883(0.3)$ & $6.38(5.41-7.53)$ \\
\hline Men & $107(1.8)$ & $23,943(0.3)$ & $6.11(5.04-7.39)$ \\
\hline Women & $35(1.9)$ & $15,940(0.2)$ & $8.09(5.81-11.28)$ \\
\hline Disorders due to sedatives & $281(3.6)$ & $73,576(0.5)$ & $9.04(8.03-10.17)$ \\
\hline Men & $193(3.2)$ & $33,215(0.5)$ & $9.56(8.29-11.02)$ \\
\hline Women & $88(4.7)$ & $40,361(0.6)$ & $8.86(7.17-10.94)$ \\
\hline Disorders due to stimulants & $178(2.3)$ & $44,223(0.3)$ & $9.60(8.28-11.14)$ \\
\hline Men & $132(2.2)$ & $27,469(0.4)$ & $8.62(7.26-10.24)$ \\
\hline Women & $46(2.5)$ & $16,754(0.2)$ & $13.21(9.86-17.71)$ \\
\hline Disorders due to other substances & $361(4.6)$ & $77,117(0.5)$ & $7.34(6.61-8.15)$ \\
\hline Men & $286(4.8)$ & $49,619(0.7)$ & $7.17(6.37-8.07)$ \\
\hline Women & $75(4.0)$ & $27,498(0.4)$ & $9.01(7.16-11.34)$ \\
\hline Substance-related convictions ${ }^{\dagger}$, all & $616(7.9)$ & $467,241(3.3)$ & $2.56(2.36-2.77)$ \\
\hline Men & $551(9.2)$ & $408,439(5.7)$ & $2.51(2.31-2.73)$ \\
\hline Women & $65(3.5)$ & $58,802(0.8)$ & $4.16(3.26-5.32)$ \\
\hline Substance-related deaths ${ }^{\ddagger}$, all & $38(0.5)$ & $90,850(0.6)$ & $2.54(1.83-3.52)$ \\
\hline Men & NA & NA & NA \\
\hline Women & NA & NA & NA \\
\hline
\end{tabular}

Note: $\mathrm{NA}=$ Sex-specific results not reported due to small number of cases.

*Any substance misuse outcomes include alcohol-related disorder, any drug-related disorder, substance-related convictions, and substance-related deaths.

\# Alcohol-related disorders include the diagnoses of mental and behavioral disorders due to alcohol, alcohol-related somatic conditions, or poisonings by alcohol.

$\S$ Any drug-related disorders include the diagnoses of mental and behavioral disorders due to psychoactive drugs, drug-related somatic conditions, or poisonings by drugs. 
t Substance-related convictions include convictions of driving under the influence of alcohol or drugs and violations of the Narcotic Drugs Act [SFS 1968:64] such as possession, manufacturing, trafficking, or sales of narcotics.

¥ Substance-related deaths include the causes of death due to mental and behavioral disorders due to alcohol or other psychoactive drugs, alcohol- or drug-related somatic conditions, or poisonings by alcohol or drugs. 
Table 2. Risk of substance misuse outcomes in individuals with Tourette syndrome or chronic tic disorder, compared with unaffected individuals from the general population, excluding psychiatric comorbidities.

\begin{tabular}{|c|c|c|c|c|c|c|c|c|c|}
\hline \multicolumn{10}{|c|}{ HR $(95 \% \mathrm{CI})$, adjusted for sex and birth year } \\
\hline & $\begin{array}{l}\text { Without } \\
\text { exclusion }\end{array}$ & $\begin{array}{l}\text { Excluding } \\
\text { ADHD }\end{array}$ & $\begin{array}{l}\text { Excluding } \\
\text { conduct } \\
\text { disorders }\end{array}$ & $\begin{array}{l}\text { Excluding } \\
\text { pervasive } \\
\text { developmental } \\
\text { disorders }\end{array}$ & $\begin{array}{l}\text { Excluding } \\
\text { OCD }\end{array}$ & $\begin{array}{l}\text { Excluding } \\
\text { anxiety } \\
\text { disorders }\end{array}$ & $\begin{array}{l}\text { Excluding } \\
\text { depressive } \\
\text { disorders }\end{array}$ & $\begin{array}{l}\text { Excluding } \\
\text { psychotic } \\
\text { and bipolar } \\
\text { disorders }\end{array}$ & $\begin{array}{l}\text { Excluding } \\
\text { all } \\
\text { psychiatric } \\
\text { comorbidities } \\
\text { at the same } \\
\text { time }\end{array}$ \\
\hline $\begin{array}{l}\text { Any substance } \\
\text { misuse outcomes* }\end{array}$ & $\begin{array}{l}3.11 \\
(2.94-3.29)\end{array}$ & $\begin{array}{l}2.00 \\
(1.82-2.19)\end{array}$ & $\begin{array}{l}2.93 \\
(2.76-3.11)\end{array}$ & $\begin{array}{l}3.10 \\
(2.91-3.31)\end{array}$ & $\begin{array}{l}3.03 \\
(2.84-3.23)\end{array}$ & $\begin{array}{l}2.52 \\
(2.32-2.74)\end{array}$ & $\begin{array}{l}2.74 \\
(2.54-2.95)\end{array}$ & $\begin{array}{l}2.97 \\
(2.78-3.16)\end{array}$ & $\begin{array}{l}1.43 \\
(1.20-1.79)\end{array}$ \\
\hline $\begin{array}{l}\text { Alcohol-related } \\
\text { disorder }\end{array}$ & $\begin{array}{l}3.45 \\
(3.19-3.72)\end{array}$ & $\begin{array}{l}2.19 \\
(1.94-2.48)\end{array}$ & $\begin{array}{l}3.27 \\
(3.02-3.55)\end{array}$ & $\begin{array}{l}3.42 \\
(3.13-3.74)\end{array}$ & $\begin{array}{l}3.34 \\
(3.06-3.64)\end{array}$ & $\begin{array}{l}2.69 \\
(2.39-3.03)\end{array}$ & $\begin{array}{l}3.16 \\
(2.85-3.51)\end{array}$ & $\begin{array}{l}3.33 \\
(3.05-3.64)\end{array}$ & $\begin{array}{l}1.64 \\
(1.28-2.10)\end{array}$ \\
\hline $\begin{array}{l}\text { Any drug-related } \\
\text { disorder§ }\end{array}$ & $\begin{array}{l}6.84 \\
(6.32-7.40)\end{array}$ & $\begin{array}{l}4.44 \\
(3.86-5.10)\end{array}$ & $\begin{array}{l}6.54 \\
(6.01-7.11)\end{array}$ & $\begin{array}{l}6.58 \\
(5.98-7.24)\end{array}$ & $\begin{array}{l}6.46 \\
(5.89-7.09)\end{array}$ & $\begin{array}{l}6.24 \\
(5.63-7.32)\end{array}$ & $\begin{array}{l}6.81 \\
(6.02-7.62)\end{array}$ & $\begin{array}{l}6.58 \\
(5.99-7.23)\end{array}$ & $\begin{array}{l}2.76 \\
(1.86-4.08)\end{array}$ \\
\hline $\begin{array}{l}\text { Substance-related } \\
\text { convictions }^{\dagger}\end{array}$ & $\begin{array}{l}2.56 \\
(2.36-2.77)\end{array}$ & $\begin{array}{l}1.55 \\
(1.35-1.77) \\
\end{array}$ & $\begin{array}{l}2.40 \\
(2.20-2.61)\end{array}$ & $\begin{array}{l}2.75 \\
(2.51-3.00) \\
\end{array}$ & $\begin{array}{l}2.62 \\
(2.40-2.86)\end{array}$ & $\begin{array}{l}2.30 \\
(2.07-2.57)\end{array}$ & $\begin{array}{l}2.39 \\
(2.16-2.64)\end{array}$ & $\begin{array}{l}2.53 \\
(2.31-2.77) \\
\end{array}$ & $\begin{array}{l}1.31 \\
(1.03-1.67)\end{array}$ \\
\hline
\end{tabular}

Note: The results for substance-related deaths are not reported separately due to underpowered analysis.

* Any substance misuse outcomes include alcohol-related disorder, any drug-related disorder, substance-related convictions, and substance-related deaths.

\# Alcohol-related disorders include the diagnoses of mental and behavioral disorders due to alcohol,

alcohol-related somatic conditions, or poisonings by alcohol.

$\S$ Any drug-related disorders include the diagnoses of mental and behavioral disorders due to psychoactive drugs, drug-related somatic conditions, or poisonings by drugs.

t Substance-related convictions include convictions of driving under the influence of alcohol or drugs and violations of the Narcotic Drugs Act [SFS 1968:64] such as possession, manufacturing, trafficking, or sales of narcotics. 
Table 3. Sibling comparison for the risk of substance misuse outcomes.

HR $(95 \% \mathrm{Cl})$ adjusted for sex and birth year

Any substance misuse outcomes*

1.74

(1.53-1.97)

Alcohol-related disorder ${ }^{\#}$

1.94

$(1.65-2.29)$

Any drug-related disorder $\S$

3.17

(2.60-3.86)

Substance-related convictions ${ }^{\dagger}$

1.64

(1.36-1.98)

Note: The results for substance-related deaths are not reported separately due to underpowered analysis.

* Any substance misuse outcomes include alcohol-related disorder, any drug-related disorder, substance-related convictions, and substance-related deaths.

\# Alcohol-related disorders include the diagnoses of mental and behavioral disorders due to alcohol, alcohol-related somatic conditions, or poisonings by alcohol.

$\S$ Any drug-related disorders include the diagnoses of mental and behavioral disorders due to psychoactive drugs, drug-related somatic conditions, or poisonings by drugs.

† Substance-related convictions include convictions of driving under the influence of alcohol or drugs and violations of the Narcotic Drugs Act [SFS 1968:64] such as possession, manufacturing, trafficking, or sales of narcotics. 


\section{Figure Titles and Legends}

Figure 1. Cumulative incidence under the assumption of no competing risks estimated as 1 - the Kaplan-Meier estimate of survival function (with 95\% Cls) for different substance misuse outcomes among individuals with Tourette syndrome (TS) or chronic tic disorder (CTD) and unaffected individuals from the general population in the subsample of individuals followed up from birth $(n=5,219,597)$. Alcohol = alcohol-related disorders; Drugs = drugrelated disorders; Crimes $=$ substance-related criminal convictions; Deaths $=$ substancerelated deaths 